Article

\title{
How to Allocate the Allowance for the Aviation Industry in China's Emissions Trading System
}

\author{
Bao-Jun Tang 1,2,3,4,5 and Yu-Jie $\mathrm{Hu}{ }^{1,2,3,4,5,6, *(1)}$ \\ 1 Center for Energy and Environmental Policy Research, Beijing Institute of Technology, Beijing 100081, China; \\ tbj@bit.edu.cn \\ 2 School of Management and Economics, Beijing Institute of Technology, Beijing 100081, China \\ 3 Beijing Key Lab of Energy Economics and Environmental Management, Beijing 100081, China \\ 4 Sustainable Development Research Institute for Economy and Society of Beijing, Beijing 100081, China \\ 5 Collaborative Innovation Center of Electric Vehicles in Beijing, Beijing 100081, China \\ 6 Climate Policy, German Institute for Economic Research, Berlin 10117, Germany \\ * Correspondence: yjhu@gzu.edu.cn
}

Received: 9 April 2019; Accepted: 29 April 2019; Published: 1 May 2019

\begin{abstract}
In order to combat climate change and control emissions in the aviation industry, it is necessary to research the aviation industry's potential application of China's Emissions Trading System (ETS), especially the carbon allowance allocation (CAA). On the basis of historical and benchmarking CAA schemes, considering the responsibility, capacity, and potential of firms, this study proposes the indicators CAA (ICAA) scheme. Moreover, considering firms' costs, this study also proposes a multi-objective CAA (MCAA) scheme. Finally, the most effective scheme is reported. Results show that under ICAA and MCAA, caps are lower and basically consistent with the emissions reduction target of the "13th Five-Year Plan Work Program for Controlling GHG Emissions of Civil Aviation in China" and international goals. Different types of airlines gain different quotas according to their income and the number and age of their aircraft. The cost of reducing emissions in each scheme is less than $0.35 \%$ of their total costs. Under the ICAA-S, ICAA-P, and MCAA schemes, airlines can achieve a reduction in emissions of $19.7 \%, 20.9 \%$, and $19.6 \%$, respectively. Moreover, under MCAA, the difference in quotas between airlines is smaller. Therefore, of the schemes evaluated, MCAA is the most effective.
\end{abstract}

Keywords: Carbon allowance allocation schemes; aviation industry; China

\section{Introduction}

In 1990, the first Intergovernmental Panel on Climate Change (IPCC) report indicated that global climate change and greenhouse gas emissions posed an imminent threat [1]. In recent years, increased human activities have caused approximately $1.0^{\circ} \mathrm{C}$ of global warming compared with the pre-industrial temperature. This increase in temperature has potential impacts on biodiversity and ecosystems, with associated risks to health, livelihoods, food security, water supply, human security, and economic growth [2]. Moreover, global warming and the recently increased frequency of extreme weather events have threatened the social and environmental sustainability of human beings. Therefore, to combat climate change and achieve sustainable development, many countries in the world have been implementing adaptation and mitigation options. The Emissions Trading System (ETS), also known as cap and trade, is a market-based approach to controlling pollution through the use of caps and providing economic incentives for reducing the emission of pollutants [3]. It was put forward in the Kyoto Protocol [4] for countries to cost-effectively reduce greenhouse gas (GHG) emissions, has aroused a widespread and heated discussion around the world. The ETS is also a mechanism to 
facilitate meeting the global target for GHG emissions reduction by allocating and trading within the restricted emissions space [5]. Thus, the primary task in carbon market construction has become solving the core problem of how to set caps and allocate allowances [6,7], which are related to the effectiveness of the total emissions space and participants sharing the responsibility of emissions reduction.

China has been the world's largest emitter since 2007 [8], and the country bears responsibility for emissions reduction and is under pressure from international public opinion. In 2015, the Chinese government announced its Intended Nationally Determined Contributions, which specify that $\mathrm{CO}_{2}$ emissions will peak around the year, 2030, or as soon as possible, and carbon dioxide emissions have declined by 60\% to 65\% since 2005 [9]. On the basis of this emissions cap, on 19 December 2017, China's Emissions Trading System (CETS) was officially launched to effectively reduce emissions. Firms in the CETS will receive (free allocation) and buy (auction) the emissions allowances (emissions permits) from the Chinese government, and they can ensure that their final emissions do not exceed their emission permits by trading permits. CETS, which has surpassed the EU ETS as the world's largest carbon market [10], is in its initial phase and only covers the power industry; it will make progress to covering additional sectors in later stages [11]. Thus, it is necessary to conduct research on the ETS and its allowance allocation for other sectors, including the aviation sector.

The global aviation industry accounts for $7 \%$ of the emissions of the transportation industry, which is the second-ranking emitter among all sectors, and the International Civil Aviation Organization (ICAO) forecasts that aviation carbon emissions in 2050 will have increased by 3 to 7 times those in 2005 [12]. Moreover, carbon emissions in China's aviation industry are increasing very quickly; its emissions in 2015 were 29.8 times those in 1971, and they have been gradually exceeding the emissions levels of the UK, Germany, and other European countries since 2010 (Figure S1) [13]. To control aviation carbon emissions and meet emissions-reducing goals (1. Improving fuel efficiency by an average of $1.5 \%$ annually to 2020; 2 . Capping net emissions through carbon-neutral growth from 2020 (CNG2020); 3. Cutting net emissions in half by 2050, compared with 2005 [14]. In the 13th five-year plan period, the average carbon dioxide emissions will drop by more than $4 \%$ of those in the 12 th five-year plan period [15].), many countries started to include the aviation industry in their ETS, such as the EU ETS, the ETS in New Zealand and South Korea, as well as some Chinese carbon market pilots, such as those in Shanghai, Guangdong, and Fujian [16]. Therefore, with the development of CETS, it is necessary to research the aviation industry within the CETS context to determine its cap and the participants sharing the responsibility of emissions reduction.

In order to control carbon emissions and help governments allocate the burden to regions, countries, provinces, and firms, scholars have proposed many schemes. Some of them are based on equity by using indicators, such as population, emissions, energy, GDP, GDP per capita, historical cumulative emissions per capita, energy consumption intensity, and other indicators [17-23]. They have compared different allocation principles and attempted to achieve equitably. On the basis of multiple indicators that were built on the principles of equity, as reported by Rose et al. and Ringius et al. [17-19], Han et al. [23] proposed a cap-and-trade allocation scheme for the road transport sector. In this study, the principles of equity were used to select indicators that are fitting for the aviation industry and adjust the cap setting in an aim to develop our Indicators of Carbon Allowance Allocation (ICAA) scheme.

Specifically, for allowance allocation in the aviation industry, scholars considering the efficiency and costs of firms' emissions reduction have evaluated allocation schemes and proposed a few strategies, most of which were based on specific routes in Europe, by adopting optimization methods, such as data envelopment analysis modeling, nonlinear programming, or multi-objective optimization models as well as other optimization methods. However, the proposed models' hypotheses are usually too ideal, and the schemes are not universally applicable and are difficult to implement [5,24-29]. Morrell [24] focused on a method of allocating emissions permits in the EU context, and three UK airlines were selected for evaluating three main types of allocation: Grandfathering, auctioning, and benchmarking. Qiu et al. [29] investigated carbon emissions allowance allocations for air passenger 
transport and proposed a bi-level multi-objective model that was based on a specified route. Cadarso et al. [30] proposed a new methodology based on an input-output model for quantifying the impact of international freight transport on total pollution by sector and assigning responsibility to consumers in Spain. Leenders et al. [31] studied the allocation of $\mathrm{CO}_{2}$ emissions to a specific shipment in routing transportation in Europe. Chin et al. [32] proposed an alternative permit allocation method that was built on the Cournot model to simulate the aviation industry under the EU and augmented EU emissions trading schemes. Therefore, in this study, emissions reduction efficiency and firms' costs were also considered to work out a multi-objective CAA scheme for China using an adjusted hypothesis, which ensures that this scheme is generalizable, easy to operate, and not based on a specific route.

Because of the many ETSs that cover the aviation industry and CETS plans to cover it, and given the core problem of how to set the cap and allocate the allowance in accordance with the effectiveness of the total emissions space and the participants sharing the responsibility of emissions reduction, this study's aim is to work out an effective allowance allocation scheme to reduce emissions by using the results of previous studies. On the basis of historical and benchmarking CAA (HCAA and BCAA) schemes and the responsibility, capacity, and potential of firms, the indicators of CAA scheme were developed in this work. Moreover, on the basis of firms' costs, the multi-objective CAA scheme was also established in this study. The different schemes were evaluated, and the most effective CAA scheme was selected. The remainder of this article is organized as follows. Section 2 discusses the research framework. Section 3 introduces the research method, and Section 4 presents the results. Section 5 draws the research conclusions and proposes policy recommendations.

\section{Research Framework}

Figure 1 shows the research framework for solving the allowance allocation problem for the aviation industry in China's Emissions Trading System. Firstly, on the basis of the emissions of the aviation industry, its development, its emissions reduction targets, and the fact that many ETSs cover this sector, this paper examines the application of China's ETS to the aviation industry, particularly carbon allowance allocation (CAA), with the aim of working out a fair and efficient carbon allowance allocation scheme. On the basis of historical and benchmarking CAA schemes and the responsibility, capacity and potential of firms, the indicators of CAA scheme were established. Also, on the basis of firms' costs, a multi-objective CAA scheme was created. The accounting models, integrated weighting model, and multi-objective genetic algorithm were used to determine the results. The results are first discussed in terms of quotas, actual emissions, and emissions reduction in different firms under different schemes. Secondly, according to the classification of firms, the reasons that different types of firms gain a different number of quotas were analyzed. Finally, depending on whether the schemes help firms reduce their emissions effectively and share the reduction responsibility fairly, the most effective and fair CAA scheme was selected. Overall, this study proposes an effective and fair carbon allowance allocation scheme for the aviation industry in China. 


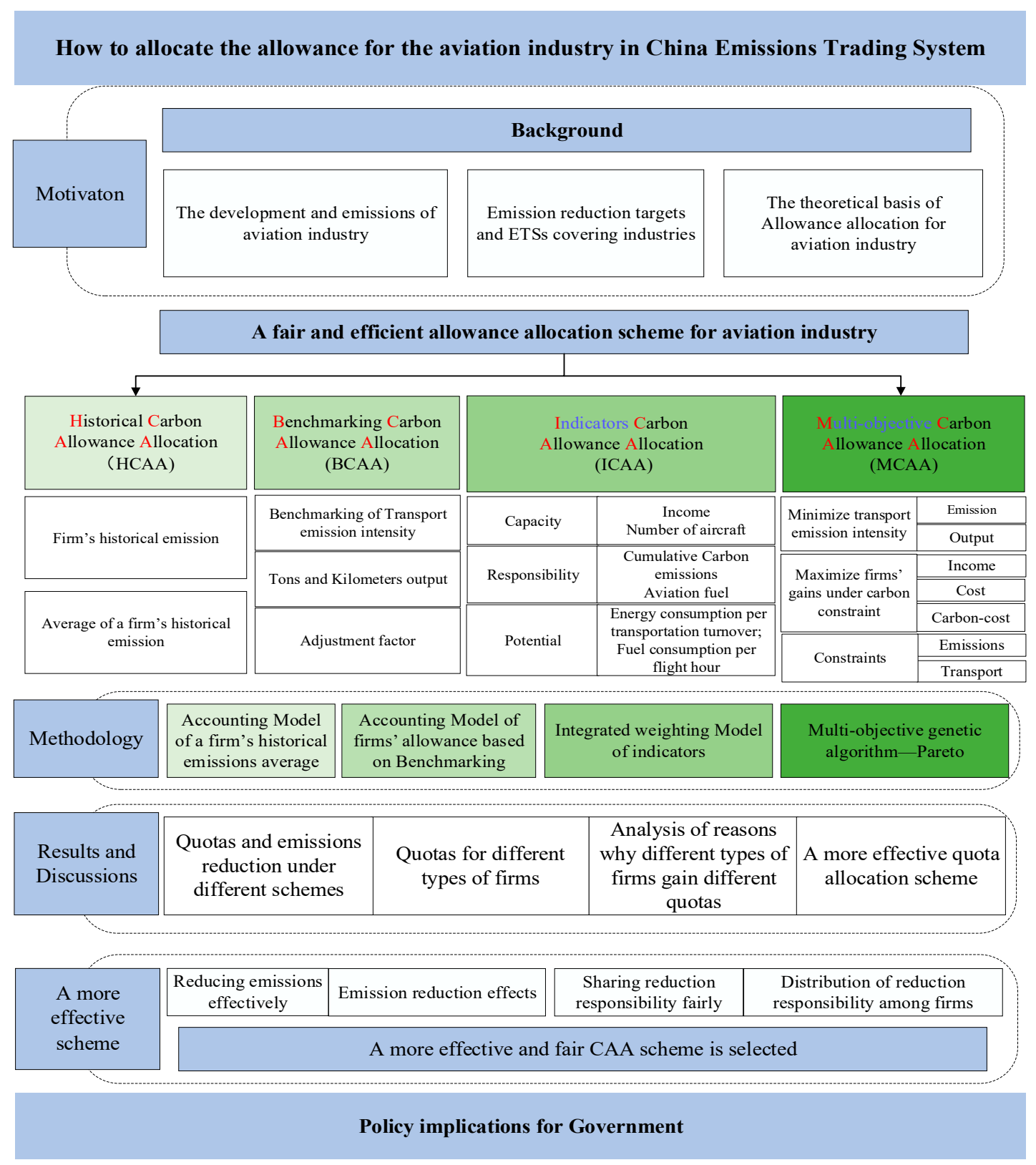

Figure 1. The framework of carbon allowance allocation for the aviation industry.

\section{Methodology}

In this study, to calculate the quotas of firms in the aviation industry, traditional methods were used, namely, grandfathering and benchmarking. Then, on the basis of the responsibility, capacity, and potential of firms, the indicators of CAA method were established. On the basis of firms' costs, a multi-objective CAA method was also created.

\subsection{Accounting Model: Grandfathering}

Grandfathering [3,33-38], i.e., firms' historical emissions quotas in a base year or base period, involves quotas that are equal to the average of a firm's historical emissions. In this scheme, the quotas 
in 2019 would be obtained according to the average values of the historical emissions from 2014 to 2016 for different firms, as shown in Equations (1) and (2):

$$
\begin{gathered}
E_{i}^{T}=1 /\left(m-t_{0}+1\right) \cdot \sum_{t=t_{0}}^{m} E_{i}^{t}, \\
E_{i}^{2019}=1 / 3 \cdot \sum_{t=2014}^{2016} E_{i^{\prime}}^{t}
\end{gathered}
$$

where $E_{i}^{T}$ represents the result of the quota of firm $i$ in year $T$ and is determined by the average emissions value from $t_{0}$ to $m$; and $E_{i}{ }^{2019}$ represents the result of the quota of firm $i$ in 2019 and is determined by the average emissions value of the firm from 2014 to 2016.

\subsection{Accounting Model: Benchmarking}

In benchmarking $[33,39,40]$, i.e., firms' benchmarking method, the quotas are equal to the benchmarking firm's emissions intensity multiplied by the annual intensity reduction factor and the tons and kilometers of the output of firms. The quota value is derived as follows:

$$
E_{i}^{T}=B M^{(T-1)} \times \operatorname{CSCF}^{(T-1)} \times T_{i}^{T},
$$

where $E_{i}^{T}$ represents the result of the quota of firm $i$ in year $T . B M^{(T-1)}$ represents the benchmarking of firms' emissions intensity in year $(T-1)$, which is the best firm' s carbon emissions intensity. $\operatorname{CSCF}^{(T-1)}$ represents the adjustment factor of carbon intensity and is determined by the "Civil Aviation Administration of China Energy Conservation and Emissions Reduction 13th Five-Year Plan". $T_{i}^{T}$ represents the forecasted tons and kilometers of the output of firms $i$ in year $T$ and is estimated based on its historical average growth rate.

\subsection{Integrated Weighting Model of Indicators}

The integrated weighting model of indicators is a top-down model that relies on the fairness principle. Firstly, the cap-namely, the total of all quotas-should be worked out. According to the "Civil Aviation Administration of China Energy Conservation and Emissions Reduction 13th Five-Year Plan", the five-year average of carbon dioxide emissions is declining by more than $4 \%$ of that of the emissions from 2011 to 2015 . Therefore, the reduction target is set to $5 \%$, and the cap is set as follows:

$$
C A P^{T}=\sum_{i}^{n}\left(95 \% \times 1 /\left(m-t_{0}+1\right) \cdot \sum_{t=t_{0}}^{m} E_{i}^{t}\right) .
$$

This equation means that the cap is equal to the sum of $95 \%$ of firms' average emissions from 2014 to 2016. Secondly, indicators are selected from three dimensions: Capability, responsibility, and potential. Thirdly, four scenarios are generated by assigning different weights to the indicators. Finally, different scenarios are calculated separately.

\subsubsection{Constructing an Indicator System for Allowance Allocation}

On the basis of the fairness principle, indicators were selected from the dimensions of capability, responsibility, and potential. In terms of firms' development capacity, this study focused on their income and number of aircraft. This means that the more capable a company is, the more responsibility it needs to bear; this is in line with the vertical principle, as demonstrated in previous studies [17-19]. In terms of firms' responsibility, this study examined their cumulative carbon emissions and aviation fuel consumption. Therefore, the more companies emitted in the past, the more emissions they need to reduce; this is an application of the equality principle and the vertical principle, as demonstrated 
previously [17-19]. Concerning firms' potential, practical indicators were selected that can predict a firm's potential to reduce future emissions, by improving energy efficiency, adjusting their energy structure, and investing in science and technology [21,23]. Two indicators were applied, namely, energy consumption per ton and kilometer output and fuel consumption per flight hour (as shown in Table 1).

Table 1. Indicators' system for allowance allocation.

\begin{tabular}{|c|c|c|}
\hline Dimension & Indicator & Explanation \\
\hline Capacity & $\begin{array}{c}\text { Income } \\
\text { Number of aircraft }\end{array}$ & $\begin{array}{l}\text { The more capable a company is, the more } \\
\text { responsibility it has to bear (vertical). }\end{array}$ \\
\hline Responsibility & $\begin{array}{l}\text { Cumulative carbon emissions } \\
\text { Aviation fuel consumption }\end{array}$ & $\begin{array}{l}\text { The more companies emitted in the past, the more } \\
\text { emissions they need to reduce (equality). }\end{array}$ \\
\hline Potential & $\begin{array}{l}\text { Energy consumption per ton and } \\
\text { kilometer output }\end{array}$ & $\begin{array}{l}\text { The less energy-efficient a firm is, the more potential } \\
\text { it has to reduce emissions. }\end{array}$ \\
\hline
\end{tabular}

\subsubsection{Setting Up Four Quota Scenarios by Different Weights}

In terms of the weights allocated to the indicators of capacity, responsibility, or potential, the variation coefficient method was used, as shown by Equations (5) and (6):

$$
\begin{gathered}
C V_{j}=\sigma_{x_{i j}} / \bar{x}_{i j}, \\
w_{j}=C V_{j} / \sum_{j=1}^{n} C V_{j},
\end{gathered}
$$

where $C V_{j}$ represents the variation coefficient of indicator $j, \sigma_{x i j}$ represents the standard deviation of the values of indicator $j$ of firm $i, \bar{x}_{i j}$.presents the average of the values of indicator $j$ of firm $i$, and $w_{j}$ represents the weight allocated to indicator $j$ of capacity, responsibility, or potential.

Then, four quota scenarios were set up by different weights: The equal weight scenario, preferred capacity scenario, preferred responsibility scenario, and preferred potential scenario. The first scenario is the equal weight scenario, in which the weights are $33.33 \%$ on average. The second scenario is the preferred capacity scenario, in which the capacity indicators are assigned by $60 \%$, and the rest are assigned by $20 \%$ each. The third scenario is the preferred responsibility scenario, in which the responsibility indicators are assigned by $60 \%$, and the rest are assigned by $20 \%$ each. The fourth scenario is the preferred potential scenario, in which the potential indicators weigh $60 \%$, and others weigh $20 \%$ (as shown in Table 2).

Table 2. Weights of indicators under four decision preference cases.

\begin{tabular}{ccccc}
\hline Four Preference Cases & $\begin{array}{c}\text { Equal } \\
\text { Weight }\end{array}$ & $\begin{array}{c}\text { Preferred } \\
\text { Capacity }\end{array}$ & $\begin{array}{c}\text { Preferred } \\
\text { Responsibility }\end{array}$ & $\begin{array}{c}\text { Preferred } \\
\text { Potential }\end{array}$ \\
\hline Capacity (A) & 0.33 & 0.6 & 0.2 & 0.2 \\
Responsibility (B) & 0.33 & 0.2 & 0.6 & 0.2 \\
Potential (C) & 0.33 & 0.2 & 0.2 & 0.6 \\
Capacity + Responsibility + Potential & 1 & 1 & 1 & 1 \\
(A + B + C) & & & & \\
\hline
\end{tabular}

\subsubsection{Integrated Weighting Model}

From the different scenarios with different weights, the composite indicator was calculated on the basis of the firms' sub-indicators in the different scenarios by using Equations (7)-(9), namely, the integrated weighting model, and the results of quotas were obtained:

$$
\begin{gathered}
a_{i j}, b_{i j}, c_{i j}=x_{i j} / \max \left(x_{j}\right), \\
R_{i}=W_{A}\left(w_{a 1} \times a_{i 1}+w_{a 2} \times a_{i 2}\right)+W_{B}\left(w_{b 1} \times b_{i 1}+w_{b 2} \times b_{i 2}\right)+W_{C}\left(w_{c 1} \times c_{i 1}+w_{c 2} \times c_{i 2}\right),
\end{gathered}
$$




$$
E_{F i}{ }^{(t+1)}=E_{i}{ }^{t}-R_{i} \times c^{2}{ }^{R},
$$

where $R_{i}$ represents the composite quota indicator of firm $i ; W_{A}$ is the weight of capacity; $W_{B}$ is the weight of responsibility; $W_{C}$ is the weight of potential; $w_{(a, b, c) j}$ represents the weight allocated to indicator $j$ in scenario $\mathrm{A}, \mathrm{B}$, or $\mathrm{C} ; a_{i j}$ is the standard values of firm $i$ for indicator $j$ of capacity; $b_{i j}$ is the standard values of firm $i$ for indicator $j$ of responsibility, $c_{i j}$ is the standard values of firm $i$ for indicator $j$ of potential; cap $^{R}$ represents the cap of emissions reduction; $E_{i}{ }^{t}$ means the emissions of firm $i$ in year $t$; and $E_{F i}{ }^{(t+1)}$ means the free allowance of firm $i$ in year $(t+1)$.

\subsection{Multi-Objective Model of Carbon Allowance Allocation}

\subsubsection{Conceptual Model of MCAA}

The government allocates quotas according to firms' historical emissions. When the actual emissions of the firms in the current period exceed their quotas, they enter the emissions trading system to purchase additional quota. In the ETS, the government aims to reduce emissions by minimizing the emissions intensity, but firms try to maximize their gains by increasing their income and reducing their costs, including carbon cost. Also, there are still some uncertain factors in the market, such as carbon price and other variables (Figure S2).

\subsubsection{Model Objectives and Constraints}

The government aims to reduce emissions by minimizing the emissions intensity, which in turn depends on the full performance of the airlines. However, firms try to maximize their gains, which are calculated by using Equations (10) and (11):

$$
\begin{gathered}
\min \left(\max _{i} E_{i} / T_{i}\right), \\
\max \sum_{i}\left(p_{i} T_{i}-C_{i}-p_{c} E_{t i}\right),
\end{gathered}
$$

where $E_{i}$ means the actual emissions of firm $i ; T_{i}$ indicates the total turnover of transportation of firm $i$, namely, in tons and kilometers; $P_{i}$ represents the price per instance of transportation of firm $i$ and is equal to the average of their historical price; $C_{i}$ is the cost of firm $i ; P_{c}$ represents the carbon price, which is $30 \mathrm{RMB}$ according to China's ETS; and $E_{t i}$ is the emissions trading volume. There are some constraints on emissions, such as the cap, actual emissions, and emissions reduction.

The cap constraints are calculated by:

$$
E_{C}=\sum_{i} E_{F i}+\sum_{i} E_{t i}
$$

where $E_{c}$ means the cap, namely, the total quota and is forecasted by using Equation (4); $E_{F i}$ is the free allowance volume of firm $i$. Therefore, the cap is equal to the total amount of all firms' trading and free quotas.

The actual emissions and emissions reduction constraints are calculated by:

$$
\left\{\begin{array}{l}
E_{i}=T_{i} \times\left(Q_{f u e l}^{c O_{2}} / T_{i}\right) \times F_{f u e l}^{c 0_{2}} \\
E_{i}^{\min } \leq E_{F i} \\
E_{F i} \leq E_{i} \\
E_{i}^{\min }=80 \% \times \min \left(E_{i}^{T-1}, E_{i}^{T-2}, E_{i}^{T-3}\right) \\
E_{t i}=E_{i}-E_{F i}=E_{t i}{ }^{+}-E_{t i}{ }^{-} \\
E_{t i}{ }^{+} \times E_{t i}{ }^{-}=0 \\
0 \leq E_{t i}{ }^{-} \leq E_{F i}, E_{t i}{ }^{+} \geq 0 \\
E_{i} \geq 0, E_{F i} \geq 0, E_{t i} \geq 0
\end{array}\right.
$$


where $Q_{f u e l}^{c O_{2}}$ is the quantity of fuel that is emitting $\mathrm{CO}_{2}$, and $F_{\text {fuel }}^{c o_{2}}$ is the emissions factor, which indicates the $\mathrm{CO}_{2}$ emissions of the fuel's combustion; $E_{i}{ }^{\mathrm{min}}$ represents the minimum emissions of firm $i$, which is $80 \%$ of the minimum actual emissions in the past 3 years; $E_{t i}{ }^{+}$is the amount of allowance that firm $i$ purchases; $E_{t i}{ }^{-}$is the amount of allowance that firm $i$ sells. The above equations indicate that the free quota must not exceed the actual emissions and, in order to guarantee firms' development, the free quota cannot be less than $80 \%$ of the historical average of the actual emissions. Finally, the quota sold by firms must not exceed the free quota gained (trading is limited to the aviation sector in the model).

Also, there are some constraints on firms' transportation capacity in the aviation industry as follows. These include firms' development and the speed of their development:

$$
\left\{\begin{array}{l}
T_{i} \geq d_{i}^{\min } \\
T_{i} \leq d_{i}^{\max } \\
d_{i}^{\min }=\min \left(T_{i}^{T-1}, T_{i}^{T-2}, T_{i}^{T-3}\right) \\
d_{i}^{\max }=120 \% \times \max \left(T_{i}^{T-1}, T_{i}^{T-2}, T_{i}^{T-3}\right)
\end{array},\right.
$$

where $d_{i}^{\min }$ is the minimum value of the total turnover of firm $i$ in the past three years, and $d_{i}^{\max }$ is $120 \%$ of the maximum value in the total turnover of firm $i$ in the past three years and indicates that it helps them continue their development.

In addition, some non-negative constraints are:

$$
E_{i} \geq 0, E_{F i} \geq 0, E_{t i} \geq 0
$$

Finally, two decision variables were determined. The first is the allowance, which is decided by the government with the goal of minimizing the emissions and transportation turnover, i.e., tons and kilometers of the output is decided by airlines that want to ensure a reasonable or increasing amount of turnover and reduce the cost of emissions by upgrading their technology to maximize the benefits. The overall model is as follows, and the parameters and variables are described in Table S1:

$$
\begin{aligned}
& \min \left(\max _{i} E_{i} / T_{i}\right), \max \sum_{i}\left(p_{i} T_{i}-C_{i}-p_{c} E_{t i}\right) \\
& \text { s.t. }\left\{\begin{array}{l}
E_{C}=\sum_{i} E_{F i}+\sum_{i} E_{t i} \\
E_{C}=0.95 \times \sum_{i} \operatorname{Average}\left(E_{i}^{T-1}, E_{i}^{T-2}, E_{i}^{T-3}\right) \\
E_{i}=T_{i} \times\left(Q_{f u e l}^{c c_{2}} / T_{i}\right) \times F_{f u e l}^{c o_{2}} \\
E_{i}^{\min } \leq E_{F i} \\
E_{F i} \leq E_{i} \\
E_{i}{ }^{\min }=80 \% \times \min \left(E_{i}^{T-1}, E_{i}^{T-2}, E_{i}^{T-3}\right) \\
E_{t i}=E_{i}-E_{F i}=E_{t i}{ }^{+}-E_{t i}{ }^{-} \\
E_{t i}{ }^{+} \times E_{t i}{ }^{-}=0 \\
0 \leq E_{t i}{ }^{-} \leq E_{F i}, E_{t i}{ }^{+} \geq 0 \\
T_{i} \geq d_{i}^{\min } \\
T_{i} \leq d_{i}^{\max } \\
d_{i}^{\min }=\min \left(T_{i}^{T-1}, T_{i}^{T-2}, T_{i}^{T-3}\right) \\
d_{i}^{\max }=120 \% \times \max \left(T_{i}^{T-1}, T_{i}^{T-2}, T_{i}^{T-3}\right) \\
E_{i} \geq 0, E_{F i} \geq 0, E_{t i} \geq 0
\end{array}\right.
\end{aligned}
$$

\subsubsection{Solution Algorithm}

To solve the multi-objective problem, scholars have proposed different algorithms. To effectively prevent falling into a local optimum, a genetic algorithm is typically used to solve the problem. Genetic algorithms are based on the application of genetic iteration to search for the optimal solution [41,42]. Since 1985, when the United States held the first international conference on genetic algorithms, the 
algorithm has been continuously developed and applied to solve optimization and computing problems in the science, engineering, computer, and artificial intelligence areas [43-46]. Moreover, the genetic algorithm is also applied in the field of multi-objective optimization and has experienced relatively systematic development, and due to the complexity of the multi-objective optimization problem, this method has been continually improved [47-50]. The improved non-dominated sorting algorithm was selected and applied in this study (shown in Figure S3). This algorithm was used by Majumdar et al. [51] to solve a generalized assignment problem and applied by $\mathrm{Xu}$ et al. [28] to the power sector's allowance allocation in China. It is most likely to generate a truly multi-objective optimization evolutionary algorithm using the concept of a Pareto optimality search for the non-inferior optimal solution set [52]. Thus, the selected algorithm helped us work out the Pareto optimal series solution.

\subsection{Data Sources}

On the basis of transportation volume and income, six airlines were selected for our empirical analysis. The selected airlines are China Eastern Airlines (CEA), China Southern Airlines (CSA), Air China (AC), Hainan Airlines (HA), Spring Airlines (SA), and Juneyao Airlines (JA). Four of them are state-owned firms, and two of them are private firms with the best development. The six airlines occupy $92 \%$ of the total transportation volume and $83 \%$ of the total income in the aviation industry.

The data sources for the airlines' fuel consumption and airlines' carbon emissions are from the Airlines Social Responsibility Report (2014-2016), China Civil Aviation Corporation Greenhouse Gas Emissions Accounting Method, and Reporting Guide. The income, cost, and number of aircraft of the airlines are from annual reports (2014-2016), while the tons and kilometers of output and the price of per instance of transportation are from the Civil Aviation Industry Development Statistics Bulletin (2014-2016) and civil aviation data are from statistics (2014-2016). The aviation emission reduction target is from Civil Aviation Energy Conservation and Emissions Reduction's "13th Five-Year Plan" and some other institutions, such as IEA, ICAO, IATA, and CAAC.

\section{Results and Discussions}

\subsection{Comprehensive Comparison and Classification Analysis of Firms' Results}

\subsubsection{CSA Gains the Highest Quota, Followed by AC and CEA, While JA has the Lowest Quota}

According to the results of the historical carbon allowance allocation scheme, CSA has the highest quota because of its high historical emissions, but, based on its actual emissions, it has the most responsibility for emissions reduction. The differences between the quota and the predicted actual emissions mean that CSA needs to reduce 433.7 million tons of emissions. JA obtains the lowest quota, and SA has the least responsibility for emissions reduction at a quota of 60.21 million tons. According to results of the BCAA scheme, the total quota would decrease by $21.48 \%$ compared with the actual emissions in 2019, which requires firms to take effective actions to improve their energy efficiency and promote emissions reduction while developing. Of the studied airlines, SA has weak transportation performance and slow development, and its quota is the most restrictive. It needs to reduce emissions by $35.16 \%$. Because CSA has the newest and most efficient aircraft, it has the highest quota, but in terms of its actual emissions, it needs to further reduce emissions by $27.14 \%$, followed by CEA and AC. HA obtained surplus quota, $8.4 \%$ of emissions, because of its rapid business development in recent years. JA's development demand and relatively small scale require further improvement in its energy efficiency.

The ICAA scheme was applied to different scenarios, and the results are in terms of firms' capacity, responsibility, and potential. Although CSA needs to take the most responsibility for emissions reduction, it obtains the highest quota - between 20.2 million tons and 20.4 million tons-because of its high emissions. CSA is followed by AC, CEA, and HA. SA and JA obtained lower quotas, which amounted to less than 2 million tons. This study compared the quotas with the actual emissions, and 
the result shows that the quotas of the six airlines are lower than the actual emissions; an average reduction of $20 \%$ is achieved, and the total emissions are reduced by $15 \%$. Comparing the quotas obtained for the airlines in the four scenarios reveals that large-scale airlines, such as CEA, CSA, and $\mathrm{AC}$, have lower quotas in the preferred capability and responsibility scenarios, in which the emissions constraints are tighter.

The MCAA results show that CSA has the highest quota, i.e., 20.11 million tons, followed by AC, CEA, HA, and JA, the latter of which has the lowest quota, i.e., 1.64 million tons. A comparison between the quotas and actual emissions shows that the average quota is lower than $20 \%$ of the actual emissions. CEA has the largest reduction in emissions. JA has the lowest quota, but has the highest proportion of emissions reductions. Also, a difference exists between the solution value, which was worked out on the basis of airlines' emissions constraints and profit-making goals, and the actual predicted value of output in tons and kilometers. HA is tightly constrained and needs to reduce 22.17 million tons and kilometers or technologically upgrade to meet emissions constraints at the same volume level.

Overall, under the different schemes, CSA gains the highest quota, followed by AC and CEA, while JA has the lowest quota. Under the individual schemes, CEA and SA gain higher quotas under HCAA, CEA has a lower quota under MCAA, and SA has a lower quota under BCAA. AC and CSA have lower quotas under BCAA, CSA has a higher quota under ICAA-P, and SA has a higher quota under MCAA. JA and HA have higher quotas under BCAA and have lower quotas under ICAA-P (Figure 2).

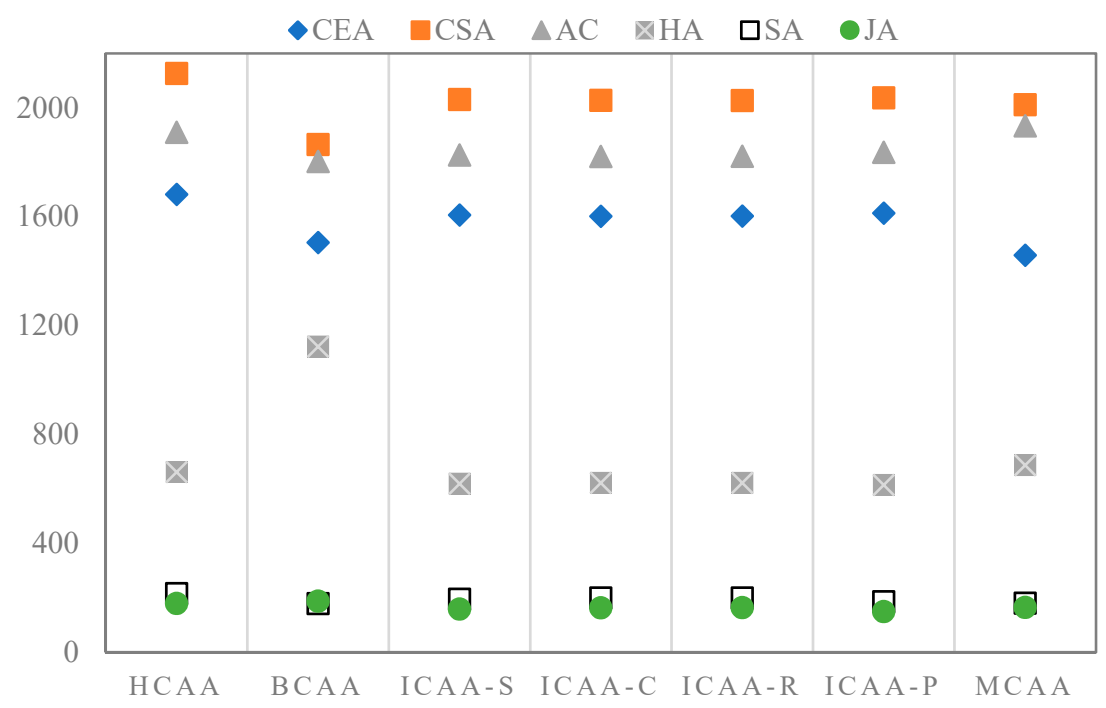

Figure 2. Comparison of quotas obtained by the six airlines under different allocation schemes.

\subsubsection{Categories of Six Airlines}

The firms were classified as shown in Figure S2. Firstly, four of them are state-owned firms and two of them are private firms. Secondly, according to their income and aircraft, AC, CSA, and CEA are bigger airlines, among which CSA is the biggest, with an income of $114.8 \mathrm{RMB}$ billion and 702 aircraft in 2016, followed by AC and CEA. Thirdly, according to the average growth rate of income, HA, SA, and JA are considered the faster-developing firms. HA is the fastest growing, with a 30\% growth rate, followed by JA and SA. Finally, in terms of the average age of the aircraft, HA, SA, and JA are also considered younger firms, among which JA is the youngest, with an average aircraft age of 3.84 years, followed by SA and HA. 


\subsubsection{Analysis of Reasons for Different Types of Firms Gaining Different Quotas}

On the basis of the firms' classification, this paper further analyzed why different types of firms gain different quotas. In addition to greater caps, firms gain higher quotas according to their type and the scheme used (HCAA or BCAA). Because of state-owned firms' transportation strategy in China, they consume more energy and generate high emissions, whereas private firms have lower historical emissions and aim to grow their business.

According to their scale, their speed of development, and the age of their aircraft, it was found that under BCAA, ICAA-S/C/R, or MCAA, smaller, faster, and younger airlines gain higher quotas because of their faster development, lower historical emissions, younger aircraft, and lower overall and carbon costs. HA, SA, and JA have made many efforts to remedy inefficient development and reduce emissions. For example, HA eliminated old aircraft and built a young and efficient fleet to optimize aircraft performance (reduced weight, renovated wings, and adjusted center of gravity) and upgrade aircraft flight emissions reduction technology and ground reduction measures. SA, the low-cost airline with a single aircraft (A320), renovated aircraft wings, included a water washing engine, used a ground moving source instead of an APU (aircraft engine auxiliary power unit), and reduced aircraft weight. JA has a young fleet of unified aircraft (A320 and B737), as well as professional management and operation.

The larger, slower, and older firms are the opposite, but because of their technology upgrades and energy efficiency, they gain more under ICAA-P. AC, CSA, and CEA have made many efforts toward aircraft and operational optimization and fuel-saving measures. For example, CEA renovated aircraft wings and transmitters, included a water washing engine, used a ground moving source instead of an APU, retired old aircrafts, employed big data in the management of their operation, and applied energy monitoring platform settings. AC introduced the new B787-9 energy-saving aircraft and reduced aircraft weight, implemented aircraft and ground fuel savings, and introduced new energy-efficient vehicles on the ground. CSA has reduced the average age of aircraft by replacing or selling old aircraft and introducing a new generation of "green" aircraft (B787-9, B737-max, and A320neo), optimized route, aircraft performance, and planning (adjusted center of gravity and reduced weight), and implements accurate delivery.

\subsection{Quotas Results Achieve National and International Emissions-Reducing Goals}

This section, using the Quota results, discusses whether the airlines achieved the emissions-reducing goals. Figure 3 indicates that, under the emissions constraints of different quotas schemes, the aviation industry can effectively cut emissions by $18 \%$ and achieve national and international emissions-reducing goals. Further, emissions are reduced the most under ICAA-P, with an average reduction of $20 \%$, followed by MCAA, ICAA-S, and so on. Comparing the percentage of actual emissions reduction with those estimated under different schemes, it is seen that CSA, SA, JA, and $\mathrm{AC}$ have smaller emissions reduction burdens because they have already started to take measures to reduce their emissions. Also, HA's emissions are still growing quickly and need more attention (Figure 3).

The emissions constraints in different quota schemes help airlines achieve international emission reduction targets for different time points, for example, cutting net emissions in half compared with the levels in 2005. Figure 4 shows that under ICAA and MCAA, the aviation industry can achieve its emissions-reducing goals earlier (2027), and under HCAA and BCAA, it needs more time. Under different quotas schemes, the smaller, faster, and younger firms, such as HA, SA, and JA, need more time to achieve emissions-reducing goals and CSA, AC, and CEA can achieve emissions-reducing goals earlier because of their scale and efficiency (Figure 4). 


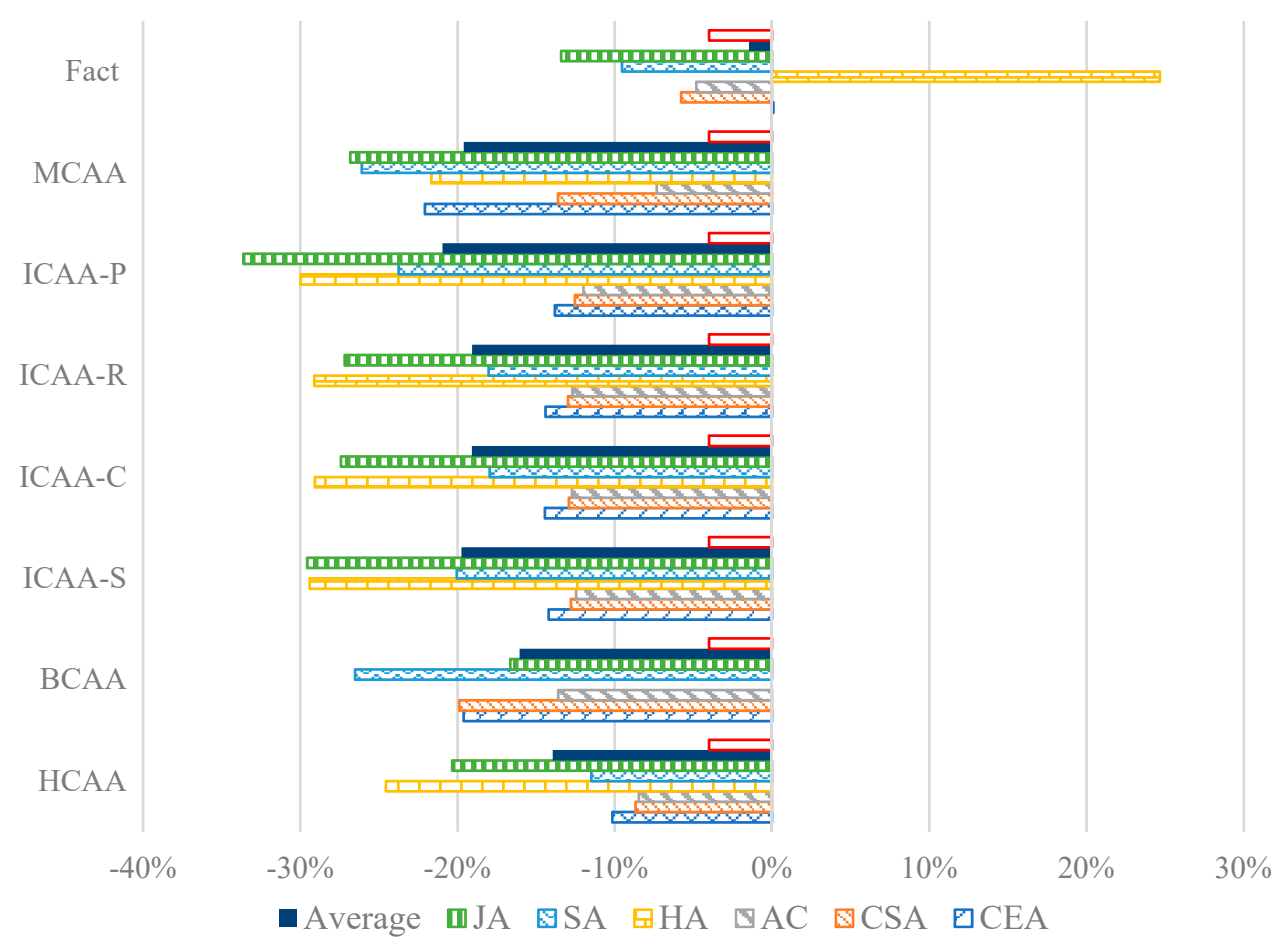

Figure 3. The emissions reduction percentages under different schemes.

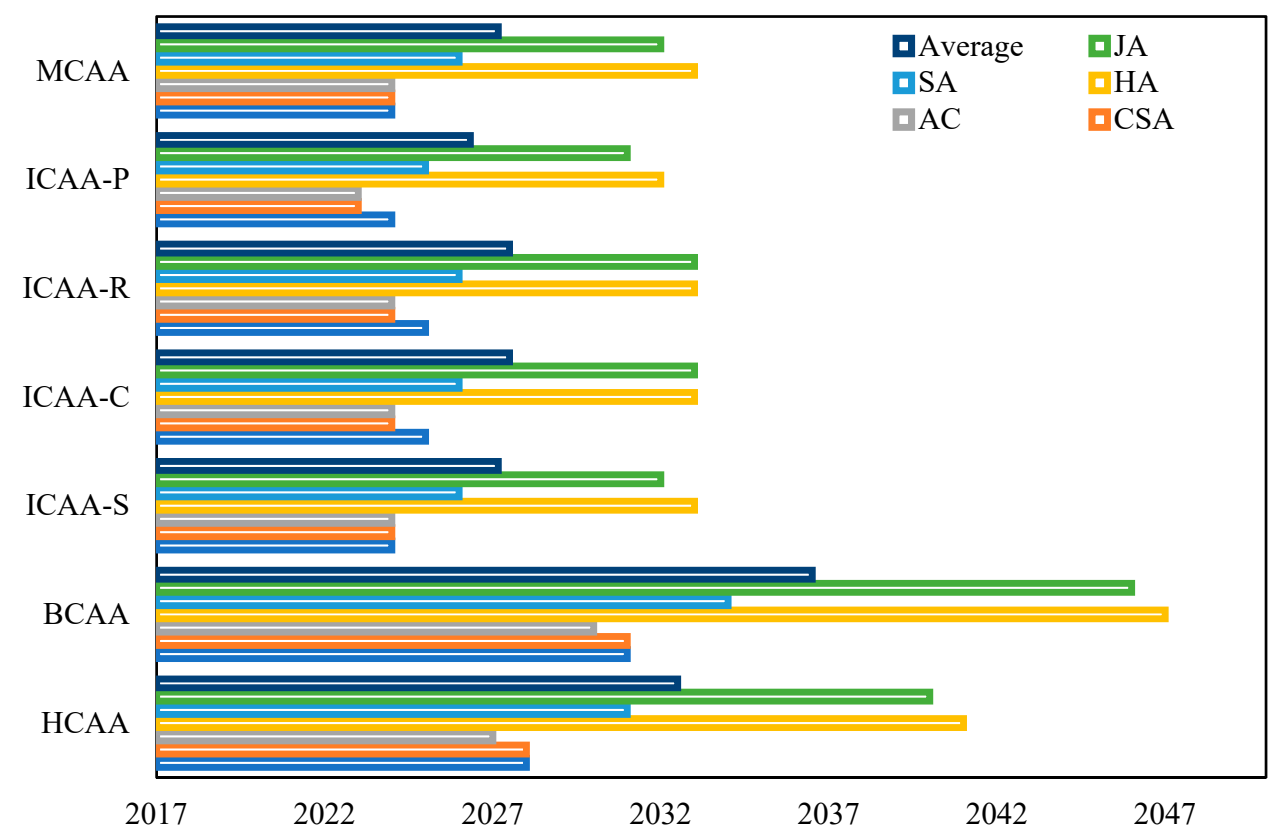

Figure 4. The time to achieve international emissions-reducing goals under different schemes.

\subsection{A More Effective Quota Allocation Scheme}

Finally, considering whether the discussed schemes help firms reduce emissions effectively and share the reduction responsibility fairly, this paper compares the quota allocation schemes and presents the most effective one (Figure 5). 


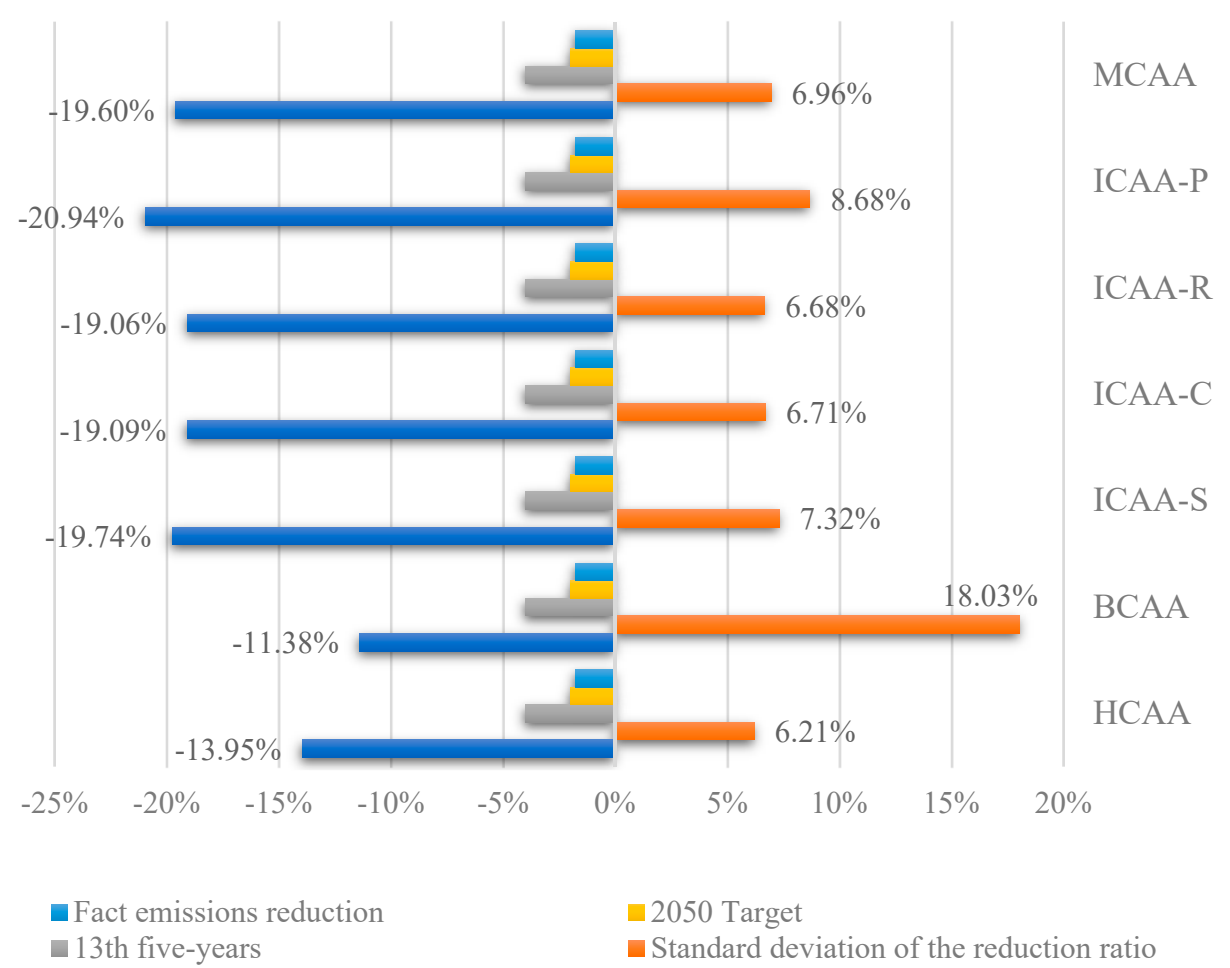

Figure 5. The average emissions reduction ratio and distribution of allowance under different schemes.

In Figure 5, the blue bars indicate the average emissions reduction percentage for a scheme. The gray and yellow bars show the emissions reduction targets of China and the world, respectively, and the differences between the gray, yellow, and blue bars indicate that all schemes achieve carbon emissions constraint targets, but they do so differently. ICAA-S, ICAA-P, and MCAA have higher average emissions reduction ratios, i.e., $19.74 \%, 20.94 \%$, and $19.60 \%$, respectively. Thus, the three schemes are more effective in reducing emissions. Then, the green bars show their actual emissions reduction ratios, and the differences between the blue bars and green bars indicate the potential for reducing emissions effectively. If the difference is large, then it is harder to meet the constraints of the schemes. It is found that the ICAA-P and ICAA-S schemes are harder to carry out. Also, the orange bars, which indicate the standard deviation of the emissions reduction percentage among the airlines, show the distribution of emissions reduction responsibilities. Under MCAA, the difference in quotas between airlines is small at only $6.96 \%$. Therefore, the multi-objective solution is considered to be the better one of the three.

In addition, in terms of the costs to reduce emissions under different schemes (Figure 6), it is seen that the percentage of the cost to reduce emissions is less than $0.35 \%$ of all costs, which is very little expense. The ICAA-P scheme costs the most, followed by ICAA-R/S/C, MCAA, BCAA, and HCAA. Only under MCAA and BCAA will CEA and CSA (larger firms) share the cost with HA, SA, and JA (small and fast-developing firms). Under the other schemes, HA, SA, and JA bear more costs. Under the MCAA scheme, when the carbon price goes up by $33.33 \%$ (from 30 RMB to 120 RMB), the profits of the airlines decrease from $0.81 \%$ to $0.86 \%$; when the carbon costs increase by $100 \%$, the profits of the airlines decrease by $3.33 \%$; when carbon costs increase by $200 \%$, the loss of firms' profits is $5.97 \%$; and when carbon costs increase by $300 \%$, the loss of firms' profits is $7.81 \%$ (Figure S5). Although the increase in carbon costs does cause a decline in firms' profits, firms can achieve emissions reduction, and the loss caused due to the increased carbon price is small and increases slowly. Besides, firms can compensate for their loss by upgrading their technology and improving their energy efficiency. Therefore, the MCAA scheme is attractive and persuasive for firms. Overall, the multi-objective CAA scheme is considered the most effective scheme of those considered. 


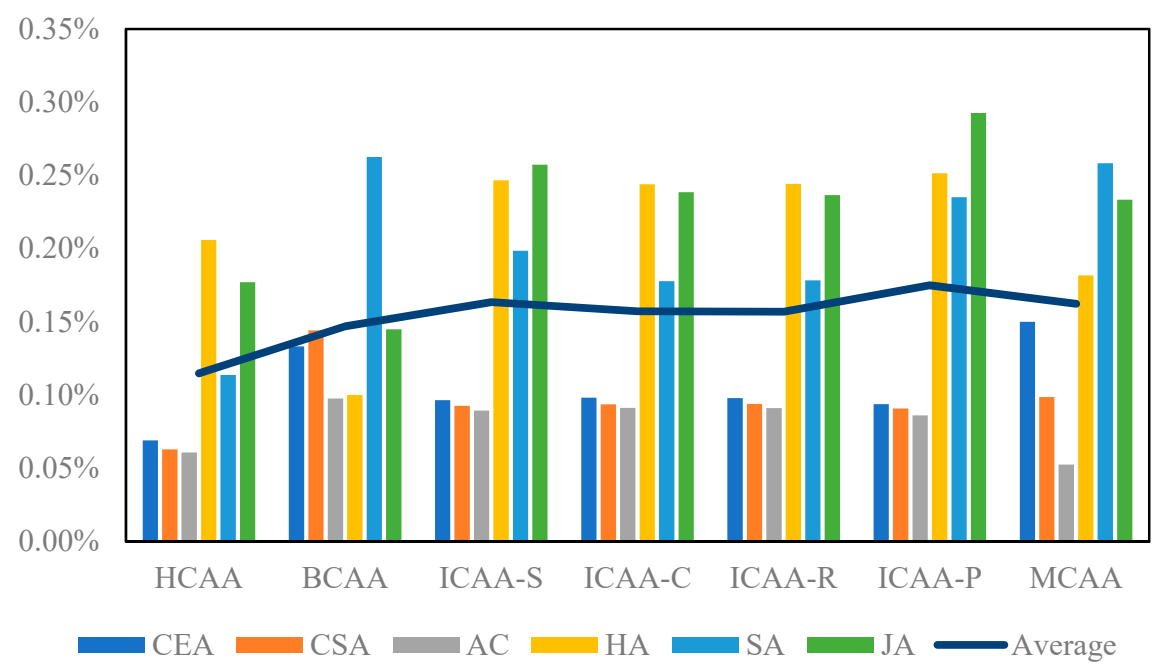

Figure 6. The ratio of costs to reduce emissions under different schemes.

To summarize, from the above comprehensive comparison, the classification analysis of the results, and the effect and costs of the different schemes, it is concluded that the proposed multi-objective CAA scheme is the scheme that most effectively helps firms reduce emissions and share the reduction responsibility fairly. MCAA focuses more on the cost and development of firms. In the future, it can be applied to research on the allowance allocation of firms in other industries by adjusting the parameters to fit their characteristics and achieve the same objectives, namely, minimizing the emissions intensity and maximizing gains. These are the goals that cater to the demand of CETS, which plans to cover more industries and determine their allocation schemes.

\section{Conclusions and Policy Implications}

\subsection{Conclusions}

This paper, as one of the preliminary studies on this issue, proposes an effective initial carbon allowance allocation scheme that is based on the allocation principle and method of fairness and efficiency for the aviation industry, although it can be applied to other industries in the future. A goal of this study is to examine several schemes and determine whether they help firms reduce emissions effectively, share the reduction responsibility fairly, and minimize costs to reduce emissions. According to the comparison of the results, different types of airlines gain different quotas under different schemes on the basis of their performances. Also, all schemes achieve national and international emissions-reducing goals at a lower cost. Among the schemes examined, MCAA is the most effective.

Taking all allocation schemes together, CSA obtained the highest quota (1864.79 (BCAA)-2036.03 (ICAA-P)), followed by AC, CEA, and HA, while JA obtained the lowest quotas (149.09 (ICAA-P)-187.19 (BCAA)).

Because state-owned firms have a transportation strategy that translates to high energy consumption, under HCAA and BCAA, they need more allowance. Because private firms have lower historical emissions and operate to ensure their development, they also gain more allowance. According to firms' scale, speed of development, and age of their aircraft, under ICAA-C/R and MCAA, smaller, faster-developing, and younger firms gain more allowance because of lower historical emissions, faster development, younger aircraft, and lower costs, including carbon cost. On the contrary, the larger, slower-developing, and older firms have less allowance under ICAA-C/R, and they gain more allowance under ICAA-P because of technological upgrading and energy efficiency.

Under the emissions constraints of different quota schemes, the aviation industry can cut emissions effectively by $18 \%$, and achieve the national "13th Five-Year Plan" and international emission-reducing 
goals, namely, a 4\% reduction in emissions (relative to 2011-2015), carbon-neutral growth, and cutting net emissions in half compared with the levels in 2005. Comparing the emissions-reducing results, under the ICAA-S, ICAA-P, and MCAA schemes, airlines can reduce more emissions to achieve $19.7 \%$, $20.9 \%$, and $19.6 \%$ in emissions reduction, respectively. Under MCAA, the difference in quotas between airlines is smaller.

The percentage of the cost to reduce emissions is less than $0.35 \%$ of all costs, and the ICAA-P scheme requires the most cost, followed by ICAA-R/S/C, MCAA, BCAA, and HCAA. Only under MCAA and BCAA will CEA and CSA (larger firms) share the cost with HA, SA, and JA (small and fast-developing firms). Under other schemes, HA, SA, and JA bear more cost. In terms of the firms' cost for emissions reduction, to prevent airlines from passing the carbon costs to consumers (in the form of higher ticket prices), it might make sense for the government to pay attention to the normal price. Also, under the MCAA scheme, when carbon costs increase by $300 \%$, the loss of firms' profits is only $7.81 \%$, meaning that firms can achieve emissions reduction and that the losses caused by increased carbon costs are small and increase slowly.

\subsection{Policy Implications}

The MCAA and ICAA schemes can better help us achieve the national "13th Five-Year Plan" and international emissions-reducing goals-a $4 \%$ reduction in emissions, carbon-neutral growth, and cutting net emissions in half compared with those in 2005-in the aviation industry. The percentage of the cost to reduce emissions is less than $0.35 \%$ of all costs. In terms of the firms' cost for emissions reduction, to prevent the airlines from passing the carbon cost to consumers (in the form of higher ticket prices), it might make sense for the government to pay attention to the normal price.

The allocation principle of helping firms reduce emissions effectively and share reduction responsibility fairly was used to guide our scheme designs and select the better scheme among HCAA, BCAA, ICAA, and MCAA for the aviation sector. The most effective quota allocation scheme was determined to be the MCAA scheme, as it can help firms reduce emissions effectively, share the reduction responsibility fairly, and minimize the losses of firms, with a higher average emissions reduction percentage, i.e., $19.60 \%$, and a smaller difference between the distributed emissions reduction responsibilities, i.e., 0.07 .

Under different allocation methods, the quota results differed, and the most suitable allocation method for emissions reduction and firms' development was selected. The HCAA scheme benefits firms with high historical emissions. The BCAA scheme is adopted to control the total emissions effectively, but it is affected by the scale of the growth of firms. Under the ICAA and MCAA schemes, quotas are associated with stronger emissions reduction constraints. The ICAA-C scheme will help some small-scale and fast-growing firms to obtain high quotas for their development; the ICAA-P and MCAA schemes are favorable for large-scale or highly energy-efficient firms aiming to effectively promote their technology upgrades and emissions reduction.

Supplementary Materials: The following are available online at http://www.mdpi.com/2071-1050/11/9/2541/s1, Figure S1: Carbon emissions of transportation and aviation industry, Figure S2: The conceptual model of MCAA in the aviation industry, Figure S3: The solution process of multi-objective genetic algorithm, Figure S4: Categories of 6 airlines, Figure S5: Relationship between the carbon price and firms' profits, Table S1: Description of parameters and variables.

Author Contributions: Conceptualization, B.-J.T.; methodology, B.-J.T. and Y.-J.H.; software, Y.-J.H.; validation, B.-J.T.; formal analysis, B.-J.T.; investigation, Y.-J.H.; resources, B.-J.T.; data curation, Y.-J.H.; writing-original draft preparation, B.-J.T. and Y.-J.H.; writing — review and editing, Y.-J.H.; visualization, Y.-J.H.; supervision, B.-J.T.; project administration, B.-J.T.; funding acquisition, B.-J.T.

Funding: This research was funded by the National Natural Science Foundation of China, grant number 71573013, 71521002, and 71642004; the Beijing Natural Science Foundation of China, grant number 9152014; the Special Items Fund for Cultivation and Development of Beijing Creative Base, grant number Z171100002217023; the Key Project of Beijing Social Science Foundation Research Base, grant number 15JDJGA084; the National Key R\&D Program, grant number 2016YFA0602603; the Special Items Fund of Beijing Municipal Commission of Education. 
Acknowledgments: We gratefully acknowledge that Jörn C. Richstein and Karsten Neuhoff from Climate Policy department in the German Institute for Economic Research helped us improve this paper.

Conflicts of Interest: The authors declare no conflict of interest.

\section{References}

1. IPCC. The First Assessment Report (FAR): Impacts Assessment of Climate Change. Available online: https://www.ipcc.ch/report/ar1/wg2/ (accessed on 1 May 2019).

2. IPCC. Special Report: Global Warming of $1.5^{\circ} \mathrm{C}$. Available online: https://www.ipcc.ch/sr15/ (accessed on 1 May 2019).

3. Stavins, R.N. Experience with Market-Based Environmental Policy Instruments. Resour. Future 2001, 11, $1-58$.

4. The Kyoto Protocol-Status of Ratification. Available online: https://unfccc.int/process/the-kyoto-protocol/ status-of-ratification (accessed on 1 May 2019).

5. Zhou, P.; Wang, M. Carbon dioxide emissions allocation: A review. Ecolog. Econ. 2016, 125, 47-59. [CrossRef]

6. Wikipedia. European Union Emission Trading Scheme. Available online: https://en.wikipedia.org/wiki/ European_Union_Emission_Trading_Scheme (accessed on 1 May 2019).

7. Establishing a scheme for greenhouse gas emission allowance trading within the Community and amending Council Directive 96/61/EC. Available online: https:/eur-lex.europa.eu/legal-content/EN/TXT/PDF/?uri= CELEX:32003L0087\&from=EN (accessed on 1 May 2019).

8. BP. BP Statistical Review of World Energy June 2018. Available online: https:/www.bp.com/content/dam/ bp/business-sites/en/global/corporate/pdfs/energy-economics/statistical-review/bp-stats-review-2018-fullreport.pdf (accessed on 30 April 2019).

9. Intended Nationally Determined Contributions (INDC). Available online: http://www.scio.gov.cn/xwfbh/ xwbfbh/wqfbh/2015/20151119/xgbd33811/Document/1455864/1455864.htm (accessed on 1 May 2019).

10. International Carbon Action Partnership (ICAP). Launch of Chinese national carbon market caps off milestone year for emissions trading. Available online: https://icapcarbonaction.com/images/PDFs/ICAP_ Press-Release_China.pdf (accessed on 30 April 2019).

11. National carbon emission trading market construction plan (power generation industry). Available online: http://www.ndrc.gov.cn/zcfb/gfxwj/201712/t20171220_871127.html (accessed on 1 May 2019).

12. European Commission. Reducing emissions from aviation. Available online: https://ec.europa.eu/clima/ policies/transport/aviation_en (accessed on 1 May 2019).

13. International Energy Agency (IEA). Headline Global Energy Data (2017 edition). Available online: https: //www.iea.org/classicstats/relateddatabases/worldenergystatistics/ (accessed on 1 May 2019).

14. Fact Sheet-Climate Change \& CORSIA. 2009. Available online: https://www.iata.org/pressroom/facts_figures/ fact_sheets/Documents/fact-sheet-climate-change.pdf (accessed on 1 May 2019).

15. The 13th five-year plan for energy conservation and emission reduction of Civil Aviation in China. 2017. Available online: http://www.caac.gov.cn/XXGK/XXGK/ZCFBJD/201702/t20170228_42798.html (accessed on 1 May 2019).

16. International Carbon Action Partnership (ICAP). Emissions Trading Worldwide: Status Report 2018. Available online: http://www.greengrowthknowledge.org/resource/emissions-trading-worldwide-status-report-2018 (accessed on 30 April 2019).

17. Rose, A.; Stevens, B.; Edmonds, J.; Wise, M. International Equity and Differentiation in Global Warming Policy. Environ. Resour. Econ. 1998, 12, 25-51. [CrossRef]

18. Ringius, L.; Torvanger, A.; Holtsmark, B. Can multi-criteria rules fairly distribute climate burdens?: OECD results from three burden sharing rules. Energy Policy 1998, 26, 777-793. [CrossRef]

19. Ringius, L.; Torvanger, A.; Underdal, A. Burden Sharing and Fairness Principles in International Climate Policy. Inter. Environ. Agreem. 2002, 2, 1-22. [CrossRef]

20. Ding, Z.; Duan, X.; Ge, Q.; Zhang, Z. Control of atmospheric CO2 concentrations by 2050: A calculation on the emission rights of different countries. Sci. China Ser. Earth Sci. 2009, 52, 1447-1469. [CrossRef]

21. Yi, W.-J.; Zou, L.-L.; Guo, J.; Wang, K.; Wei, Y.-M. How can China reach its $\mathrm{CO}_{2}$ intensity reduction targets by 2020? A regional allocation based on equity and development. Energy Policy 2011, 39, 2407-2415. [CrossRef] 
22. Wei, Y.-M.; Zou, L.-L.; Wang, K.; Yi, W.-J.; Wang, L. Review of proposals for an Agreement on Future Climate Policy: Perspectives from the responsibilities for GHG reduction. Energy Strategy Rev. 2013, 2, 161-168. [CrossRef]

23. Han, R.; Yu, B.-Y.; Tang, B.-J.; Liao, H.; Wei, Y.-M. Carbon emissions quotas in the Chinese road transport sector: A carbon trading perspective. Energy Policy 2017, 106, 298-309. [CrossRef]

24. Morrell, P. An evaluation of possible EU air transport emissions trading scheme allocation methods. Energy Policy 2007, 35, 5562-5570. [CrossRef]

25. Chang, C.C.; Lai, T.C. Carbon allowance allocation in the transportation industry. Energy Policy 2013, 63, 1091-1097. [CrossRef]

26. Xu, J.; Qiu, R.; Lv, C. Carbon emission allowance allocation with cap and trade mechanism in air passenger transport. J. Clean. Prod. 2016, 131, 308-320. [CrossRef]

27. Ji, X.; Li, G.; Wang, Z. Allocation of emission permits for China's power plants: A systemic Pareto optimal method. Appl. Energy 2017, 204, 607-619. [CrossRef]

28. Xu, J.; Yang, X.; Tao, Z. A tripartite equilibrium for carbon emission allowance allocation in the power-supply industry. Energy Policy 2015, 82, 62-80. [CrossRef]

29. Qiu, R.; Xu, J.; Zeng, Z. Carbon emission allowance allocation with a mixed mechanism in air passenger transport. J Environ. Manag. 2017, 200, 204-216. [CrossRef] [PubMed]

30. Cadarso, M.-Á.; López, L.-A.; Gómez, N.; Tobarra, M.-Á. $\mathrm{CO}_{2}$ emissions of international freight transport and offshoring: Measurement and allocation. Ecolog. Econ. 2010, 69, 1682-1694. [CrossRef]

31. Leenders, B.P.J.; Velázquez-Martínez, J.C.; Fransoo, J.C. Emissions allocation in transportation routes. Transp. Res. Part D Transp. Environ. 2017, 57,39-51. [CrossRef]

32. Chin, A.T.H.; Zhang, P. Carbon emission allocation methods for the aviation sector. J. Air Transp. Manag. 2013, 28, 70-76. [CrossRef]

33. ICAP. Allocation. 2019. Available online: https://icapcarbonaction.com/en/allocation (accessed on 1 May 2019).

34. Demailly, D.; Quirion, P. $\mathrm{CO}_{2}$ abatement, competitiveness and leakage in the European cement industry under the EU ETS: grandfathering versus output-based allocation. Clim. Policy 2006, 6, 93-113. [CrossRef]

35. Reguant, M.; Ellerman, A.D. Grandfathering and the endowment effect: An Assessment in the context of the Spanish National Allocation Plan; Center for Energy and Environmental Policy Research: Cambridge, MA, USA, 2008.

36. Clò, S. Grandfathering, auctioning and Carbon Leakage: Assessing the inconsistencies of the new ETS Directive. Energy Policy 2010, 38, 2420-2430. [CrossRef]

37. Knight, C. What is grandfathering? Environ. Politics 2012, 22, 410-427. [CrossRef]

38. An, J.; Lee, J. A Newsvendor Non-Cooperative Game for Efficient Allocation of Carbon Emissions. Sustainability 2018, 10, 154. [CrossRef]

39. Grubb, M.; Neuhoff, K. Allocation and competitiveness in the EU emissions trading scheme: policy overview. Climate Policy 2006, 6, 7-30. [CrossRef]

40. Zetterberg, L.; Wrake, M.; Sterner, T.; Fischer, C.; Burtraw, D. Short-run allocation of emissions allowances and long-term goals for climate policy. Ambio 2012, 41, 23-32. [CrossRef]

41. Holland, J.H. Adaptation in Natural and Artificial Systems: An Introductory Analysis with Applications to Biology, Control, and Artificial Intelligence; MIT press: Cambridge, MA, USA, 1992.

42. Davis, L. Handbook of Genetic Algorithms; Van Nostrand Reinhold (Wiley): New York, NY, USA, 1991.

43. Janikow, C.Z.; Michalewicz, Z. An Experimental Comparison of Binary and Floating Point Representations in Genetic Algorithms; International Grooving \& Grinding Association (ICGA): Greene County, NY, USA, 1991; pp. 31-36.

44. Grefenstette, J.J. Optimization of control parameters for genetic algorithms. IEEE Trans. Syst. Man, Cybern. 1986, 16, 122-128. [CrossRef]

45. Winter, G.; Periaux, J.; Galan, M.; Cuesta, P. Genetic Algorithms in Engineering and Computer Science; John Wiley \& Sons, Inc.: Hoboken, NJ, USA, 1996.

46. Miettinen, K.; Preface By-Neittaanmaki, P. Evolutionary Algorithms in Engineering and Computer Science: Recent Advances in Genetic Algorithms, Evolution Strategies, Evolutionary Programming, GE; John Wiley \& Sons, Inc.: Hoboken, NJ, USA, 1999.

47. Schaffer, J.D. Multiple objective optimization with vector evaluated genetic algorithms. In Proceedings of the First International Conference on Genetic Algorithms and Their Applications; Psychology Press: London, UK, 1985. 
48. Fonseca, C.M.; Fleming, P.J. Genetic Algorithms for Multiobjective Optimization: Formulation Discussion and Generalization. Available online: http://citeseerx.ist.psu.edu/viewdoc/summary?doi=10.1.1.48.9077 (accessed on 30 April 2019).

49. Srinivas, N.; Deb, K. Muiltiobjective optimization using nondominated sorting in genetic algorithms. Evolut. Comput. 1994, 2, 221-248. [CrossRef]

50. Deb, K.; Agrawal, S.; Pratap, A.; Meyarivan, T. A fast elitist non-dominated sorting genetic algorithm for multi-objective optimization: NSGA-II. In Proceedings of the International Conference on Parallel Problem Solving from Nature, Paris, France, 18-20 September 2000; pp. 849-858.

51. Majumdar, J.; Bhunia, A.K. Elitist genetic algorithm for assignment problem with imprecise goal. Eur. J. Oper. Res. 2007, 177, 684-692. [CrossRef]

52. Zitzler, E.; Thiele, L. An evolutionary algorithm for multiobjective optimization: The strength pareto approach. Available online: http://citeseerx.ist.psu.edu/viewdoc/summary?doi=10.1.1.40.7696 (accessed on 30 April 2019).

(C) 2019 by the authors. Licensee MDPI, Basel, Switzerland. This article is an open access article distributed under the terms and conditions of the Creative Commons Attribution (CC BY) license (http://creativecommons.org/licenses/by/4.0/). 